\title{
Neuroleptic Malign-like Syndrome Case Management in Intensive Care Unit
}

Kadir İDIN, Seniyye ÜLGEN ZENGiN, Selçuk ALVER, Harun UYSAL, Ziya SALIHOĞLU

Department of Anesthesia and Reanimation, Bezmialem Vakif University School of Medicine, İstanbul, Turkey

\section{ABSTRACT}

Neuroleptic malign-like syndrome is an emergency condition caused by the withdrawal or dose reduction of anti-Parkinsonian drugs. Quick treatment and correct diagnosis is important for saving lives. Basic clinical findings are rigidity, autonomic dysfunction, fever, elevated serum creatinine kinase levels, and confusion. In this study, we present our approach to diagnosis and treatment of a patient with neuroleptic malign-like syndrome in our intensive care unit.

Keywords: Parkinson's disease, neuroleptic malign-like syndrome, anti-Parkinsonian drugs

\section{Introduction}

Sudden discontinuation or dose reduction of dopaminergic drugs in patients undergoing Parkinson's treatment can lead to neuroleptic malignant-like syndrome (NMLS) (1). NMLS is a potentially fatal disease that includes hyperthermia, extrapyramidal symptoms, autonomic nervous system disorders, and altered consciousness symptoms (2). Although the exact mechanism remains unknown, because of the resemblance to neuroleptic malignant syndrome, the pathogenesis is considered to be similar; one of these mechanisms is the blockage of dopaminergic receptors by neuroleptics $(2,3)$.

In this case, the follow-up of NMLS, which is a serious medical emergency with a risk of high morbidity and mortality, was presented in the intensive care unit.

\section{Case Report}

A 70-year-old woman with known history of Parkinson's disease was using $450 \mathrm{mg} /$ day levodopa (50 mg tablets), $8 \mathrm{mg} /$ day ropinirole, and $60 \mathrm{mg} /$ day duloxetine. Ropinirole finished in the last week, and the patient therefore did not use it. The patient visited the emergency department with complaints of muscle rigidity in all limbs, fever, tachycardia and hypotension, and altered consciousness. In her follow-up, evaluation of blood pressure changes and laboratory examinations revealed that her body temperature was $39.8^{\circ} \mathrm{C}$, tachycardia was 110 beats $/ \mathrm{min}, \mathrm{CPK}$ was $500 \mathrm{U} / \mathrm{L}$, and leukocytosis was 14,000 . The patient, who was consulted by neurologists, was intubated and admitted to the intensive care unit when her Glasgow Coma Scale was 3. In the clinical picture, the patient was considered to have NMLS because there was an abrupt discontinuation of dopaminergic drugs. Then, $40 \mathrm{mg}$ dantrolene was intravenously started in the patient in the intensive care, and $80 \mathrm{mg}$ was given again 6 hours later; liver function tests were repeated every $6 \mathrm{~h}$, and dopaminergic drugs were initiated immediately. Due to the rise of liver function tests, dantrolene was discontinued and fluid replacement was continued. In addition, $200 \mathrm{mg} /$ day infusion of amantadine was started in the patient. Because of the development of epileptic seizures in patients, sedation was initiated with diazepam infusion. Further, $500 \mathrm{mg}$ levetiracetam was intravenously administered, and maintenance therapy was performed with $1000 \mathrm{mg} / \mathrm{day}$. On the $15^{\text {th }}$ day of hospitalization, tracheostomy was initiated, and antibiotherapy was performed according to the reproduction in the culture; percutaneous 
enteral gastrostomy was performed for feeding on the $18^{\text {th }}$ day of hospitalization. In the most recent neurological examination, GCS was noted to be 8 , and the patient was discharged for home care. Written informed consent was obtained from the patient's relatives.

\section{Discussion}

Neuroleptic malignant-like syndrome is a neurological emergency that can be fatal. The mortality rate is around $4 \%$. Diagnosis is difficult, and the most important determining factors are abrupt discontinuation and dose reduction of antiParkinson drugs. It is a condition that can be confused with hyponatremia, alcohol withdrawal syndrome, herbicide poisoning, and hydrocephalus in urgent practice $(6,7)$. Major and minor criteria that were previously determined by Levenson for NMS are used to confirm the diagnosis of this disease. Fever, elevation of serum CK, and worsening of parkinsonian signs were defined as the major criteria, while tachycardia, abnormal blood pressure values, tachypnea, loss of consciousness, excessive sweating, and leukocytosis were defined as the minor criteria. At least three major or two major and four minor criteria are required for the diagnosis of malignant syndrome. Discontinuation of the medications due to dehydration, infection, dysphagia, or hallucinations may establish a ground for NMLS.

Starting dopaminergic drugs early and in high doses is very important in treatment. Peripheral cooling application, intense hydration of the patient, and supportive treatment are needed (3, 4). Dantrolene and methylprednisolone are other drugs that can be used for therapy. It has been shown that in addition to levodopa, bromocriptine, and dantrolene treatment, intravenous administration of $1000 \mathrm{mg} /$ day methylprednisolone can shorten the duration of the disease and is effective in improving the symptoms (5). Meagher et al. (8) reported an overall recovery in the second session of ECT therapy that they initiated in a patient with MS who did not respond to drug therapy for 2 weeks; they completed the treatment in eight sessions. Venous thromboembolism is important in patients with NMLS in terms of morbidity and mortality. Prophylactic anticoagulant therapy should be started in patients who are supposed to be hospitalized for more than 12-24 h. Benzodiazepines (diazepam, chlordiazepoxide) should be given in increasing doses for sedation and muscle relaxation.

\section{Conclusion}

Neuroleptic malignant-like syndrome is a fatal condition that can occur during the treatment of Parkinson's disease. Discontinuation or reduction of dopaminergic treatment in Parkinson's patients may lead to infections or dehydration. During the follow-up, altered consciousness, increased rigidity, high fever, and elevated serum CK levels in patients are warning signs, and starting the treatment early can help overcome the risk of fatality.

Informed Consent: Written informed consent signed by patients son.

Peer-review: Externally peer-reviewed.

Author Contributions: Concept - S.Ü.Z., K.İ.; Design - S.Ü.Z., Z.S.; Supervision - K.İ., Z.S.; Resources - S.Ü.Z., S.A., H.U.; Materials - S.Ü.Z., S.A., H.U.; Data Collection and/or Processing - S.Ü.Z., S.A., H.U.; Analysis and/or Interpretation - K.İ., S.Ü.Z., Z.S.; Literature Search - S.Ü.Z., S.A., H.U.; Writing Manuscript K.İ., S.Ü.Z., Z.S.; Critical Review - K.İ., S.Ü.Z., Z.S.; Other - S.Ü.Z., S.A., H.U.

Conflict of Interest: No conflict of interest was declared by the authors.

Financial Disclosure: The authors declared that this study has received no financial support.

\section{References}

1. Yamawaki Y, Ogawa N. Successful treatment of levodopa-induced neuroleptic malignant syndrome (NMS) with disseminated intravascular coagulation (DIC) in a patient with Parkinson's disease. Rinshoshinkeigaku 1991; 31: 62-7.

2. Toru M, Matuda O, Makiguchi K, Sugano K. Neuroleptic malignant syndrome-like state following a withdrawal of anti-parkinsonian drugs. J Nerv Ment Dis 1981; 169: 324-6. [CrossRef]

3. Takubo H, Harada T, Hashimoto T, Inaba Y, Kanazawa I, Kuno S, et al. A collaborative study on the malignant syndrome in Parkinson's disease and related disorders. Parkinsonism Relat Disord 2003; 9(Suppl 1): S31-41. [CrossRef]

4. Özkan S, Özbabalık D. Parkinson hastalarında nöroleptik malign-benzeri sendrom. Parkinson Hast Hareket Boz Der 2008; 11: 36-9.

5. Sato Y, Asoh T, Metoki N, Satoh K. Efficacy of methylprednisolone pulse therapy on neuroleptic malignant syndrome in Parkinsons disease. J Neurol Neurosurg Psychiatry 2003; 74: 574-6. [CrossRef]

6. Akyürekli O, Selçuk D. Yoğunbakım olgu sunumu: Nöroleptik malign sendrom benzeri alkol yoksunluk deliryumu. Journal of Neuro Sciences 2009; 26: 251-5.

7. Çe P, Gedizlioğlu M. Herbisid zehirlenmesine bağlı bir malign nöroleptik sendrom benzeri olgu. Journal of Neuro Sciences 2005; 22: 101-3.

8. Meagher LJ, McKay D, Herkes GK, Needham M. Parkinsonism-hyperpyrexia syndrome: the role of electroconvulsive therapy. J Clin Neurosci 2006; 13: 857-9. [CrossRef] 